\title{
Laboratory culture of the freshwater benthic gastropod Bellamya aeruginosa (Reeve) and its utility as a test species for sediment toxicity
}

\author{
Taowu Ma ${ }^{1, *}$, Shuangjiao Gong ${ }^{1}$, Ke Zhou ${ }^{1}$, Cheng Zhu ${ }^{1}$, \\ Kaidong Deng ${ }^{1}$, Qinghua Luo ${ }^{1}$, Zijian Wang ${ }^{2}$ \\ 1. College of Biology and Environmental Science, Jishou University, Jishou 416000, China. E-mail: mtw922@163.com \\ 2. State Key Laboratory of Environmental Aquatic Chemistry, Research Center for Eco-Environmental Sciences, \\ Chinese Academy of Sciences, Beijing 100085, China
}

Received 28 March 2009; revised 22 July 2009; accepted 03 September 2009

\begin{abstract}
This study aimed to develop original laboratory culture and sediment toxicity testing protocols for the freshwater gastropod Bellamya aeruginosa (Reeve), a new potential species for sediment toxicity testing. B. aeruginosa was successfully cultured with an effective culture system under proposed laboratory conditions. Optimal ad libitum feeding levels for larvae, juveniles, and adults were 2.0, 6.0, and $16.0 \mathrm{mg}$ fish food/(snail-day), respectively. Mean survival rates of juveniles were higher than $90 \%$. The snails could be sexed at 9 weeks of age, and their generation time is approximately 4 months. Reproduction continued all year around; the mean fecundity was 0.55 newborn/(female-day). The utility of this species for bioassays was evaluated in both 10-day and 28-day case studies with artificial sediments. The 10-day $\mathrm{LC}_{50}$ of $\mathrm{Cu}$ for larvae was $480 \mu \mathrm{g} / \mathrm{g}$ dry weight (dw), and the lowest observed effects concentration of $\mathrm{Cu}$ for survival and growth of larvae was $195 \mu \mathrm{g} / \mathrm{g} \mathrm{dw}$. Survival and growth are reliable indicators of acute toxicity. Larvae accumulated more $\mathrm{Cu}$ than adults. B. aeruginosa exhibited a higher sensitivity to $\mathrm{Cu}$ exposure than standard test species (Hyalella azteca and Chironomus tentans). The 28-day test of sediment toxicity with adults showed that fecundity was a robust endpoint indicator of reproductive toxicity, and the biochemical endpoints of superoxide dismutase, catalase, and glutathione could be used as sensitive biomarkers for $\mathrm{Cu}$-induced oxidative damage. B. aeruginosa can be therefore recommended as a candidate for the standardization of the freshwater sediment toxicity test protocol.
\end{abstract}

Key words: gastropod; cultures; life history; lowest observed effect concentration; bioaccumulation; oxidative stress DOI: $10.1016 / \mathrm{S} 1001-0742(09) 60109-1$

\section{Introduction}

Sediments are core components of aquatic ecosystems, providing food and habitats to benthic organisms, but they are also sinks for multiple contaminants resulting from industrial discharges, urban storm-water runoff, atmospheric deposition and discharges from municipal facilities; thus they constitute a potential threat to both aquatic ecosystems and human health (Adams et al., 1992). Numerous studies have attempted to examine the ecotoxicological effects of sediment-associated contaminants on aquatic ecosystems by sediment toxicity tests (Martinez et al., 2004; Mcgee et al., 2004; Ringenary et al., 2007; Greenstein et al., 2008). Sediment toxicity tests have evolved as powerful tools that provide direct, quantifiable evidence of biological consequences of sediment contamination that can only be inferred from chemical or benthic community analyses (O'Connor and Paul, 2000; USEPA, 2000; Anderson et al., 2004). Sediment toxicity testing depends on suitable test species. To qualify for the assessment of

\footnotetext{
* Corresponding author. E-mail: mtw922@163.com
}

sediment toxicity, a species should generally meet several requirements, such as ecological importance, wide geographic distribution, year-round availability, convenient culture in the laboratory, and sensitivity to contaminants (ASTM, 2002). Current standard tests for evaluating toxicity of freshwater sediments involve a restricted number of species, such as the amphipod Hyalella azteca, the chironomid Chironomus tentans, and the oligochaete Lumbriculus variegates (USEPA, 2000; ASTM, 2003). However, in many cases, data based on toxicity testing with a very few species could not sufficiently identify the potential ecotoxicity of a wide range of contaminated sediments due to the differences of biologic traits among species. The establishment of more freshwater benthic macro-invertebrates with important ecological relevance as test species is necessary to assess the ecological risk of contaminated sediments. The gastropods are important members of aquatic ecosystems, and relatively sensitive to contaminants (Oehlmann et al., 2000; Oetken et al., 2005). Although the freshwater gastropod Lymnea stagnalis is widely used for evaluating the adverse effects of toxic chemicals or contaminants, it was suitable for water 
toxicity testing rather than for sediment toxicity testing due to its pulmonate breathing (Gomot, 1998; Leung et al., 2007). Actually, standardized sediment toxicity tests with specific freshwater gastropods have not been well defined and, therefore, generally have not been used in a regulatory context. Only recently, two prosobranch snails (Valvata piscinalis and Potamopyrgus antipodarum) have begun to be suggested as potential candidate test species for freshwater sediment toxicity assessment (Ducrot et al., 2006; Duft et al., 2007). Nevertheless, their small size (both approximately $4 \mathrm{~mm}$ long when full grown) may make it inconvenient to perform bioassays with multiendpoints; moreover, they are seldom found in Asia. In China, no native benthic macro-invertebrate species has previously been used or validated in freshwater sediment toxicity testing, and consequently an immediate is needed for seeking sediment toxicity testing species.

Recently, some attention has been given to the potential role of the freshwater mudsnail Bellamya aeruginosa (Reeve) (Mollusca: Gastropoda, Prosobranchia, Valvatidae) in monitoring environmental pollution. Xiong and You (2002) investigated oxidative stress responses of $B$. aeruginosa to contaminated river sediment in the field, and Zhang et al. (2007) used this species to detect bioaccumulation of microcystins resulting from eutrophication. $B$. aeruginosa is commonly found in various freshwater habitats of lakes, reservoirs, rivers, stream, ditches, and ponds throughout China. As a sediment-dwelling organism, it mainly inhabits soft mud with abundant organic matter (Liu et al., 1993). This species is a dominant community member of freshwater aquatic ecosystems (with density $>400$ individuals per square meter in preferred habitats) (Chen et al., 1975; Chen, 1987), and it is therefore an ecologically important representative of benthic macro invertebrates. Particularly, as it is a deposit feeder, ingesting sediment particles and organic detritus, algae and bacteria in the sediment or other substrate (Liu et al., 1993), it might be highly exposed to sediment-associated contaminants. In addition, $B$. aeruginosa plays an important role in aquatic food chain because it is a primary food item of the snail carp (Mylopharyngodon piceus), and also great importance for human consumption. Therefore, potential contaminants may be transferred from this species to higher trophic levels through the food chain. For these reasons, this freshwater gastropod might be considered as a relevant novel species for the assessment of freshwater sediment toxicity. However, the life cycle of $B$. aeruginosa under laboratory conditions has remained unknown, the procedures for assessing sediment toxicity with this species have not been reported.

The objectives of this study were therefore to reveal the life history of $B$. aeruginosa under laboratory conditions, to examine its utility as a test species for assessing sediment toxicity, and to establish protocols for laboratory culture of this species and sediment toxicity assessment.

\section{Materials and methods}

\subsection{Biology of $B$. aeruginosa}

B. aeruginosa is a branchiate gastropod. Adults are moderate-sized (with shell lengths of 20-30 mm, referring to the distance from the peristome to its opposite extremity) and are gonochorists: males are readily distinguished from females by the forniciform, stubby right tentacle, which is the copulatory organ (Fig. 1), whereas females have a pair of uniform tentacles (Liu et al., 1993). In natural habitats, the threshold water temperature for breeding is $16-18^{\circ} \mathrm{C}$, and the optimal water temperature is $24-26^{\circ} \mathrm{C}$. The reproduction is ovoviviparous; when shell lengths reach $15-16 \mathrm{~mm}(0.81-0.94 \mathrm{~g}$ in body weight), females begin to release their first newborn; the reproductive cycle is about 6 months. Adult females are gravid all year round, and can release their newborn continuously in the breeding season; the average number of newborn produced by a female in a year is approximately 50 individuals. The appearance of the newborns is not entirely similar to that of adults. Whereas shell length exceeds shell width in the adults, newborns have their shell length smaller than shell width (Chen and Song, 1975).

\subsection{Collection and acclimatization}

Original adult snails were collected in April 2006 from the clean sediments of artificial ponds full of soft mud in the Botanical Garden of Wuhan, Hubei, China, and checked for appropriate taxonomy (Liu et al., 1993) and absence of parasites. They were then transported to the laboratory in plastic pails containing site water. On reaching the laboratory, they were placed in a white tray filled with clean water; after they protruded their tentacles, males and females were separated. A maximum of 90 adults consisting of 60 females and 30 males were introduced into each culture chamber in an overlying water recirculation culture system (Fig. 2), which was modified from our previous culture systems for small fish (Ma et al., 2007). The snails were gradually acclimatized to culture conditions (Table 1), which were based on natural habitat conditions. The artificial sediment was used for acclimatization and culture since naturally clean sediment

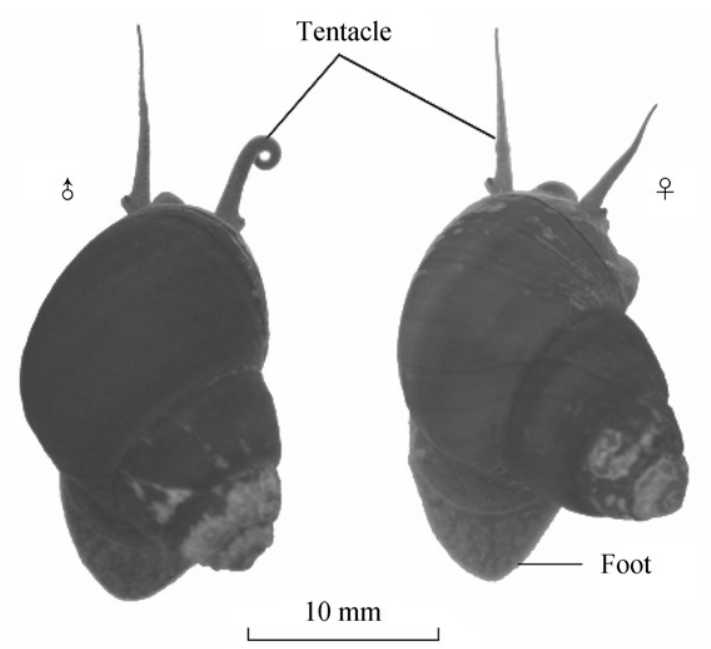

Fig. 1 Sexual dimorphism of adult Bellamya aeruginosa (The male is recognized by the forniciform, stubby right tentacle, i.e., copulatory organ). 


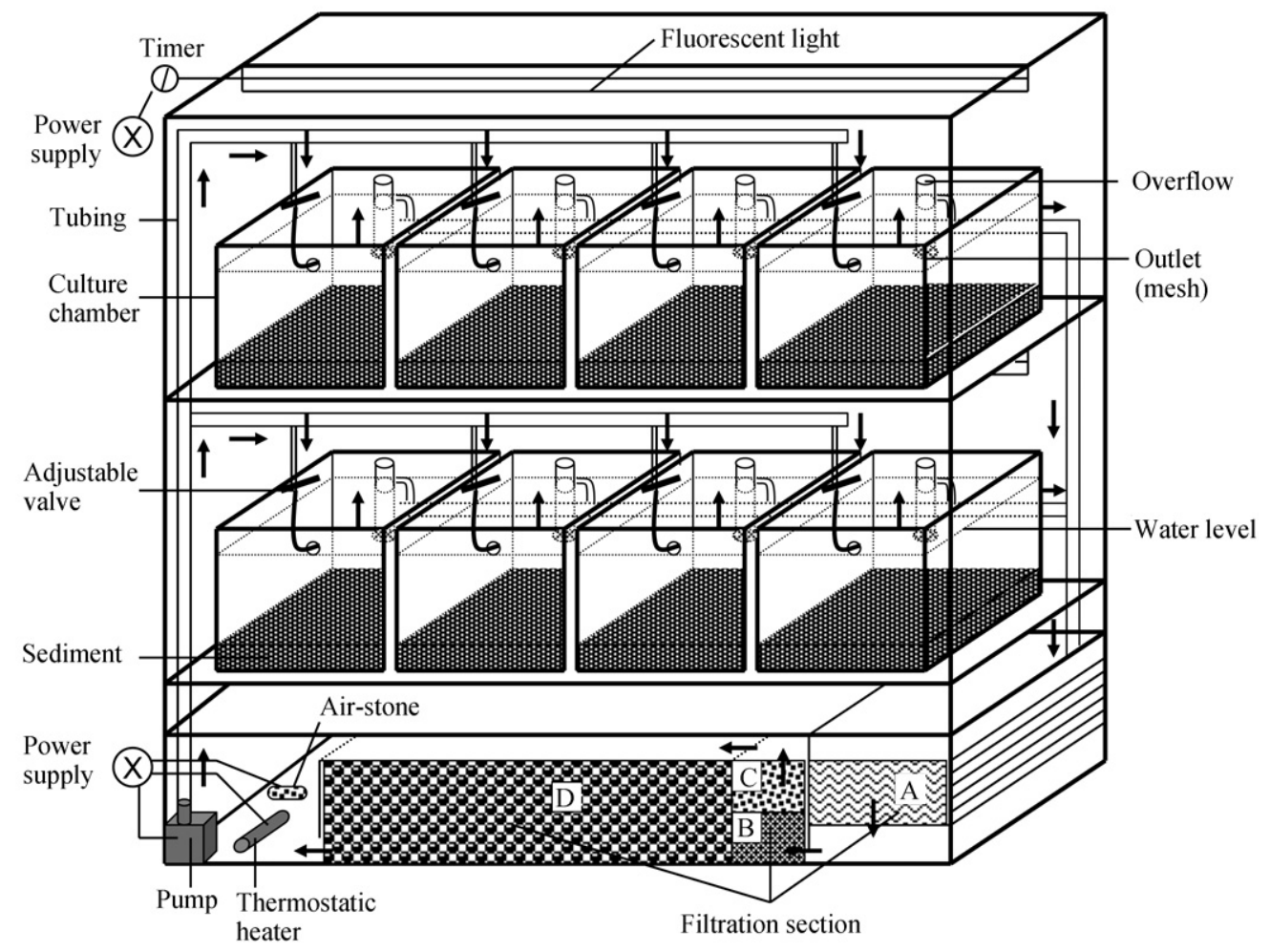

Fig. 2 Schematic of automated overlying water recirculation culture system for Bellamya aeruginosa. (A) filter cotton; (B) activated charcoal; (C) ceramic loops; (D) bio-chemical spherules.

with constant physicochemical properties is not always available for a relatively long culture period or frequent tests with this moderate-sized snail. The artificial sediment was prepared from unpolluted terrestrial soil (Pasteris et al., 2003), collected from an uncultivated plot at Dehang Nature Reserve, Jishou, China. The analysis of this soil showed low background concentrations of heavy metals (with 53.41, 31.34, 19.74, 44.98, 0.38, 18.91, and 187.76

Table 1 Culture conditions for Bellamya aeruginosa

\begin{tabular}{|c|c|}
\hline Parameter & Conditions \\
\hline Substrate (sediment) & Artificial sediment \\
\hline Temperature & $(24 \pm 1)^{\circ} \mathrm{C}$ \\
\hline Light & Wide-spectrum fluorescent lights \\
\hline Illuminance & $1000 \operatorname{lux}$ \\
\hline Photoperiod & 12L: $12 \mathrm{D}$ \\
\hline Culture chamber & $\begin{array}{l}52-\mathrm{L} \text { glass aquarium, } \\
65 \mathrm{~cm} \times 30 \mathrm{~cm} \times 27 \mathrm{~cm}\end{array}$ \\
\hline Ratio of sediment to water & $\begin{array}{l}\text { 1:4, i.e., } 7 \mathrm{~L} \text { sediment of } 6.5 \mathrm{~cm} \\
\text { in depth and } 28 \mathrm{~L} \text { water }\end{array}$ \\
\hline Overlying water & $\begin{array}{l}\text { Charcoal-filtered, dechlorinated } \\
\text { tap-water }\end{array}$ \\
\hline Overlying water quality checks & $\begin{array}{l}\text { Temperature and dissolved oxygen } \\
(\mathrm{DO} \geqslant 4.0 \mathrm{mg} / \mathrm{L}) \text { daily; } \\
\text { hardness, alkalinity, conductivity, } \\
\mathrm{pH} \text {, and total ammonia weekly }\end{array}$ \\
\hline Renewal of overlying water & $\begin{array}{l}\text { Recirculation, filtration, aeration, } \\
\text { and routine supplement for water loss }\end{array}$ \\
\hline Cleaning & Once a month \\
\hline Feeding & Ground Sanyuan ${ }^{\circledR}$ aquarium fish food \\
\hline
\end{tabular}

a Water-quality parameters (with SE): $\mathrm{pH}(7.99 \pm 0.15)$, conductivity (267 $\pm 4) \mu \mathrm{S} / \mathrm{cm}$, total ammonia $(0.41 \pm 0.05) \mathrm{mg} / \mathrm{L}$, alkalinity $(2.4 \pm 0.3)$ $\mathrm{mmol} / \mathrm{L}$, and hardness $(78.4 \pm 3.3) \mathrm{mg} / \mathrm{L}$. $\mu \mathrm{g} / \mathrm{g}$ of $\mathrm{Cr}, \mathrm{Ni}, \mathrm{Cu}, \mathrm{Zn}, \mathrm{Cd}, \mathrm{Pb}$, and $\mathrm{Mn}$, respectively), a total organic carbon (TOC) content of $4.5 \%$ and $\mathrm{pH}$ 7.78. This soil has been proved to be a suitable substrate in a pre-culture experiment. The soil was prepared as the culture substrate by a procedure modified from Pasteris et al. (2003). Briefly, after the top 1-2 cm layer of the soil was scraped and discarded with a wooden spade, the soil was collected to a depth of $20 \mathrm{~cm}$. The collected soil was dried at $80^{\circ} \mathrm{C}$ in an oven, then finely ground, and finally sieved through a $150-\mu \mathrm{m}$ nylon mesh to remove coarse particles. This processed soil was mixed $(1: 1, V / V)$ with deionized water. The resulting slurry was allowed to settle for $72 \mathrm{hr}$ at $4^{\circ} \mathrm{C}$ and then overlying water was decanted. During culture, $50 \%$ of the total volume of the substrate in each culture chamber was renewed monthly with fresh artificial sediment. The research by Ducrot et al. (2006) showed that best survival and growth of the gastropod $V$. piscinalis were obtained with aquarium fish food, and thus during the acclimatization and culture, B. aeruginosa was fed with ground aquarium fish food (Sanyuan ${ }^{\circledR}$, Beijing, China). Quality control analysis showed that levels of adverse heavy metals ( $\mathrm{Pb} 0.12 \mu \mathrm{g} / \mathrm{g}, \mathrm{Cd} 0.02 \mu \mathrm{g} / \mathrm{g}, \mathrm{Cr} 0.27$ $\mu \mathrm{g} / \mathrm{g}$ ) were far below the corresponding standard limit of the Hygienical Standard for Feeds of China (GB 130782001).

\subsection{Stock cultures}

Newborn snails were collected manually from adult stock chambers, and transferred into prepared culture chambers. Initially, a maximum of 500 newborn were added to each culture chamber. The cultures were checked 
at four-week intervals by sieving the sediment. After eight weeks, females and males were separated from the cultures, and released into separated chambers at a density of 90 snails per chamber. In the preliminary culture, the food ration and frequency of feeding for snails depended on the feeding activity of the snails and the amount of residual food. Generally, once the food on the surface of sediment was exhausted, the snails would burrow into the sediment for organic detritus, and excessive remaining food would blacken the sediment surface as it decomposed.

\subsection{Determination of ad libitum feeding levels}

The ad libitum feeding levels of $B$. aeruginosa were determined at three stages of life: larvae (7-day-old), juveniles (28-day-old), and adults (4-month-old) with tests lasting 28 days. The tests were conducted in a test system in which test chambers $(16.5 \mathrm{~cm} \times 16.5 \mathrm{~cm} \times 15$ $\mathrm{cm})$ containing $4 \mathrm{~cm}$ of clean artificial sediment were held in a temperature-controlled water bath; continuous renewal of overlying water (4-5 volume renewals/day) was implemented with a multichannel peristaltic pump (Jieheng, Chongqing, China). Each chamber was covered with a nylon lid with a hole of $5 \mathrm{~cm}$ in diameter in its center for feeding. Other conditions were the same as those of culture. Larvae were offered 1.0, 2.0, or $4.0 \mathrm{mg}$ food/(snail-day); juveniles 4.0, 6.0, 8.0, or 10 $\mathrm{mg}$ food/(snail.day); and adults $8,12,16$, or $20 \mathrm{mg}$ food/(snail-day). At each feeding level, five replicates were arranged with 50 larvae, 30 juveniles or 10 female plus 5 male adults each. The shell length growth rate of larval and juvenile snails and the fecundity (newborn/(female-day)) of adult females were measured to evaluate optimal feeding level.

\subsection{Characterization of life history}

The survival, growth and reproduction of $B$. aeruginosa were monitored in culture chambers. Under the conditions specified in Table 1, the survival and growth trial were initiated with newborn of homogenous size (shell length $(3.33 \pm 0.37) \mathrm{mm})$. These organisms came from the same birth cohort and had been reared for 7 days (freshly-born snails were not used because they are relatively weak). The snails of each life stage (larvae, juveniles, or adults) were offered fish food at the previously determined optimal feeding levels with five replicates containing 90 snails each. The survival and shell length were measured every 4 weeks; sediments were gently sieved through a $300-\mu \mathrm{m}$ mesh, survivors were counted, shell lengths were measured with a caliper, and then the survivors of each chamber were released into new chamber prepared one week before transfer organisms. The trial lasted 20 weeks, which was beyond the sexual maturation of the snails. At the end of this trial, 40 females and 20 males were randomly selected from each replicate and transferred to new chambers for another 28-day reproduction trial. When the reproduction assays ended, the sediment was sieved, and live and dead juvenile snails were counted together for the estimation of fecundity. The females were dissected and embryos were counted.

\subsection{Sediment toxicity tests}

\subsubsection{Sediment spiking}

Sediment spiking was performed following the procedures of Pasteris et al. (2003) with minor modifications. The $10 \mathrm{~g} / \mathrm{L} \mathrm{Cu}$ stock solution was prepared by dissolving analytical grade $\mathrm{CuSO}_{4} \cdot 5 \mathrm{H}_{2} \mathrm{O}$ (CAS NO 7758-98-7, Sinopharm, Shanghai, China) in deionized water (18 $\mathrm{M} \Omega \cdot \mathrm{cm})$. A series of spiking solutions were then prepared from dilutions of the stock solution. Spiking was initiated by mixing the required weight of wet artificial sediment calculated from dry/wet weight ratio with the required $\mathrm{Cu}$ solution in a glass jar at a volume ratio of 1:1. The content of each jar was manually stirred with a wooden spoon for at least $6 \mathrm{hr}$ to achieve a uniform distribution of spiked toxicants throughout the sediment, and then kept at $20^{\circ} \mathrm{C}$ for 14 days to ensure chemical equilibrium between the sediment and water (Simpson et al., 2004). The target nominal $\mathrm{Cu}$ concentrations used were 0 (control), 20, 60, 180, 540, and $1080 \mu \mathrm{g} / \mathrm{g}$ dry sediment, which covered the range of environmentally relevant $\mathrm{Cu}$ concentrations found in contaminated aquatic environments in China (Ren et al., 2007). At the beginning and end of the following tests, total particulate $\mathrm{Cu}$ concentrations in the sediment were determined by inductively coupled plasma-atomic emission spectroscopy (ICP-OES, iCAP6300 Radial, ThermoFisher Scientific, USA) after hydrochloric acid-nitric acid-perchloric acidhydrofluoric acid digestion. Two procedural blanks were also prepared with each batch of digestion set using the same analytical procedure and reagents. Certified sediment reference material (GBW 07408 (GSS-8), NRCG, China) was analyzed through the same procedure to validate the methodology, and the measured values were found within the certified range (recoveries were within $6 \%$ of the certified values). Concentrations of the metals in the sediments were expressed as $\mu \mathrm{g} / \mathrm{g}$ on a dry weight basis.

\subsubsection{Sediment toxicity test for 10 days with larvae}

The acute toxicity of the $\mathrm{Cu}$-spiked sediment to larvae was evaluated over a period of 10 days according to the test conditions described in Table 2 for all target nominal concentrations. At the start of the test, the sediment was added to each of 5 replicate test chambers per treatment to obtain a 2-cm depth; overlying water was then added gently to minimize sediment disturbance. The sediment was allowed to settle for $24 \mathrm{hr}$ for the reestablishment of redox gradients. Meanwhile, the shell lengths of homogenous 7day-old larvae were measured, and 20 active individuals were gently released into each test chamber. The snails were fed every day. On day 10, the contents of each chamber were sieved, the surviving snails were recovered and counted, and their shell lengths were measured. After depuration in clean water for $24 \mathrm{hr}$, the snails were rinsed with $10 \mathrm{mmol} / \mathrm{L}$ EDTA solution (Sinopharm, Shanghai, China) for $5 \mathrm{~min}$ to get rid of the $\mathrm{Cu}$ ions that present on their shells (Cœurdassier et al., 2005), and then transferred to a deionized water bath, and finally dried on filter paper. The snails from each replicate of the treatments were 
Table 2 Conditions for sediment toxicity testing with Bellamya aeruginosa

\begin{tabular}{|c|c|}
\hline Parameter & Conditions \\
\hline Temperature & $\begin{array}{l}(24 \pm 1)^{\circ} \mathrm{C} \text {, maintained by } \\
\text { the temperature-controlled incubator }\end{array}$ \\
\hline Light & Wide-spectrum fluorescent lights \\
\hline Illuminance & $1000 \operatorname{lux}$ \\
\hline Photoperiod & $12 \mathrm{~L}: 12 \mathrm{D}$ \\
\hline Test chamber & $\begin{array}{l}\text { 4-L glass jar }(16.5 \mathrm{~cm} \times 16.5 \mathrm{~cm} \times 15 \mathrm{~cm}) \text {, } \\
\text { covered with a nylon lid with a } 5 \text {-cm hole in } \\
\text { diameter in its center for feeding }\end{array}$ \\
\hline Sediment depth & $\begin{array}{l}\text { 10-Day larvae test: } 2 \mathrm{~cm} \\
\text { 28-Day adults test: } 4 \mathrm{~cm}\end{array}$ \\
\hline Overlying water & Charcoal-filtered, dechlorinated tap-water \\
\hline $\begin{array}{l}\text { Overlying water } \\
\text { quality checks }\end{array}$ & $\begin{array}{l}\text { 10-Day larvae test: temperature and DO daily. } \\
\text { Hardness, alkalinity, conductivity, pH, } \\
\text { and total ammonia at test initiation and } \\
\text { termination. 28-Day adults test: temperature } \\
\text { and DO daily. Hardness, alkalinity, conductivity, } \\
\text { pH, and total ammonia weekly. }\end{array}$ \\
\hline $\begin{array}{l}\text { Renewal of } \\
\text { overlying water }\end{array}$ & $\begin{array}{l}\text { Continuous renewal, } 4-5 \text { volume renewals/day, } \\
\text { implemented by an automated water-delivery } \\
\text { system adjusted by a multichannel peristaltic } \\
\text { pump (Jieheng, Chongqing, China). }\end{array}$ \\
\hline $\begin{array}{l}\text { Number of replicates/ } \\
\text { treatment }\end{array}$ & 5 \\
\hline Feeding & Ground Sanyuan ${ }^{\circledR}$ aquarium fish food, China \\
\hline
\end{tabular}

pooled for determining whole-body $\mathrm{Cu}$ burdens with ICPOES after acid digestion.

\subsubsection{Sediment toxicity test for 28 days with adults}

The effects of chronic toxicity of $\mathrm{Cu}$-spiked sediment on adult snails were evaluated over a period of 28 days according to the test conditions described in Table 2 for the following nominal concentrations: 0 (control), 20, 60, 180 , and $540 \mu \mathrm{g} / \mathrm{g}$ dry sediment. The selected adults (120 days old, mean shell length: $\sigma^{7}(17.07 \pm 0.74) \mathrm{mm}$; $q$ $(17.20 \pm 0.89) \mathrm{mm})$ that had just reached puberty were used for the test. On day 0 , the shell lengths of the snails were measured and 10 females and 5 males (based on the measured population sex ratio in the stock culture) were added to each test chamber. The snails were fed every day. Newborn visible in the test chamber were removed daily and were counted and recorded. On day 28, the contents of each test chamber were sieved and the surviving adults and their offspring were counted and recorded. The surviving adults were measured for shell length. The shells of adults were cracked with forceps, and females were inspected for gravidity (dead females were deemed to be nongravid). Then the hepatopancreas including gonad, and muscular foot were carefully separated from the visceral hump. The hepatopancreas was cut into two parts: one part was immediately frozen in liquid nitrogen and stored at $-80^{\circ} \mathrm{C}$ until further analysis, and another part of the hepatopancreas, gonad, and muscular foot were dried to constant weight at $60^{\circ} \mathrm{C}$. The $\mathrm{Cu}$ contents of these tissues were determined with ICP-OES after acid digestion. Three pivotal biomarkers including superoxide dismutase (SOD), catalase (CAT), and glutathione (GSH) in the hepatopancreas, which are involved in the primary defense against oxidative damage resulting from heavy metal stress in aquatic organisms (Livingstone, 2001), were determined using bioassay kits from Nanjing Jiancheng Bioengineering Institute (Nanjing, China) to reveal oxidative stress responses of $B$. aeruginosa to chronic exposure to $\mathrm{Cu}-$ contaminated sediments.

\subsection{Statistical analyses}

Data were analyzed with SPSS 13.0 and results are presented as mean standard deviation (SD). Concentrations of $\mathrm{Cu}$ in the sediment and snail tissues are expressed as $\mu \mathrm{g} / \mathrm{g}$ on the basis of dry weight. The endpoint values in response to $\mathrm{Cu}$ concentrations were analyzed by one-way analysis of variance (ANOVA) technique followed by post-hoc test after ensuring that the data conformed to homogeneity of variance and normality. Chi-square tests were performed to determine statistically significant differences in survival between treatments and the control. Statistical significance was declared when $P$ value was less than 0.05 . The lowest observed effects concentrations (LOECs) were determined by statistically significant differences relative to controls. The median lethal concentration $\left(\mathrm{LC}_{50}\right)$ was calculated for the 10-day assessment of acute toxicity with the trimmed Spearman-Karber method (Hamilton et al., 1977).

\section{Results}

\subsection{General observations under laboratory culture con- ditions}

The snails generally remained on the surface of the sediment when food supply was sufficient. Once the food on the sediment surface became insufficient or consumed, snails would burrow into the sediment. When dissolved oxygen in the overlying water was below $4.0 \mathrm{mg} / \mathrm{L}$, the snails crawled up the walls of the culture chambers. Under the present culture conditions, reproductive activity was maintained all year around. The newborns were generally found on the shell of an adult snail or on the walls of the culture chambers; and 2-3 days later, they inhabited the surface of the sediment. The ratio of female to male from the cultured population was around $2: 1$.

\section{2 ad libitum feeding levels}

Individual performances in the 28-day feeding test are shown in Table 3. The optimal growth rates of larval and juvenile snails were achieved when they were fed 2.0 and $6.0 \mathrm{mg}$ fish food/(snail-day), respectively. The optimal feeding level for reproduction was $16.0 \mathrm{mg}$ fish food/(snail-day).

\subsection{Life history}

Survival and growth patterns of $B$. aeruginosa are presented in Fig. 3. The survival rate of larvae was as high as $91.84 \%$; five weeks later, it remained above $80 \%$ until the end of the test, indicating the favorable culture conditions for the life cycle of $B$. aeruginosa. Under 9 weeks of age, snails grew at approximately $190 \mu \mathrm{m} /$ day (shell length) in a rapid, linear pattern. Growth $(30 \mu \mathrm{m} /$ day $)$ slowed down obviously after the onset of reproduction. No significant difference in size existed between sexes; 
Table 3 Growth and fecundity (mean \pm SD) of Bellamya aeruginosa at different life stages subject to various feeding levels during a 28-d test

\begin{tabular}{clll}
\hline Life stage & $\begin{array}{l}\text { Feeding level } \\
\text { (mg fish food/ } \\
\text { (snail·day) })\end{array}$ & $\begin{array}{l}\text { Growth rate } \\
\text { of shell } \\
\text { length ( } \mu \mathrm{m} / \text { day) }\end{array}$ & $\begin{array}{l}\text { Fecundity } \\
\text { (newborns/ } \\
\text { (female·day)) }\end{array}$ \\
\hline Larvae & 1.0 & $151 \pm 26^{\mathrm{a}}$ & - \\
(7-day-old) & 2.0 & $195 \pm 29^{\mathrm{b}}$ & - \\
& 4.0 & $191 \pm 35^{\mathrm{b}}$ & - \\
Juveniles & 4.0 & $127 \pm 18^{\mathrm{a}}$ & - \\
(28-day-old) & 6.0 & $165 \pm 13^{\mathrm{b}}$ & - \\
& 8.0 & $155 \pm 26^{\mathrm{b}}$ & - \\
Adults & 10.0 & $168 \pm 15^{\mathrm{b}}$ & - \\
(5-month-old) & 12.0 & - & $0.28 \pm 0.08^{\mathrm{a}}$ \\
& 16.0 & - & $0.46 \pm 0.12^{\mathrm{b}}$ \\
& 20.0 & - & $0.64 \pm 0.13^{\mathrm{c}}$ \\
\hline
\end{tabular}

a, b,c Mean values bearing different superscripts within a life stage differed significantly $(P<0.05$, ANOVA post-hoc Tukey's honest significance difference test).
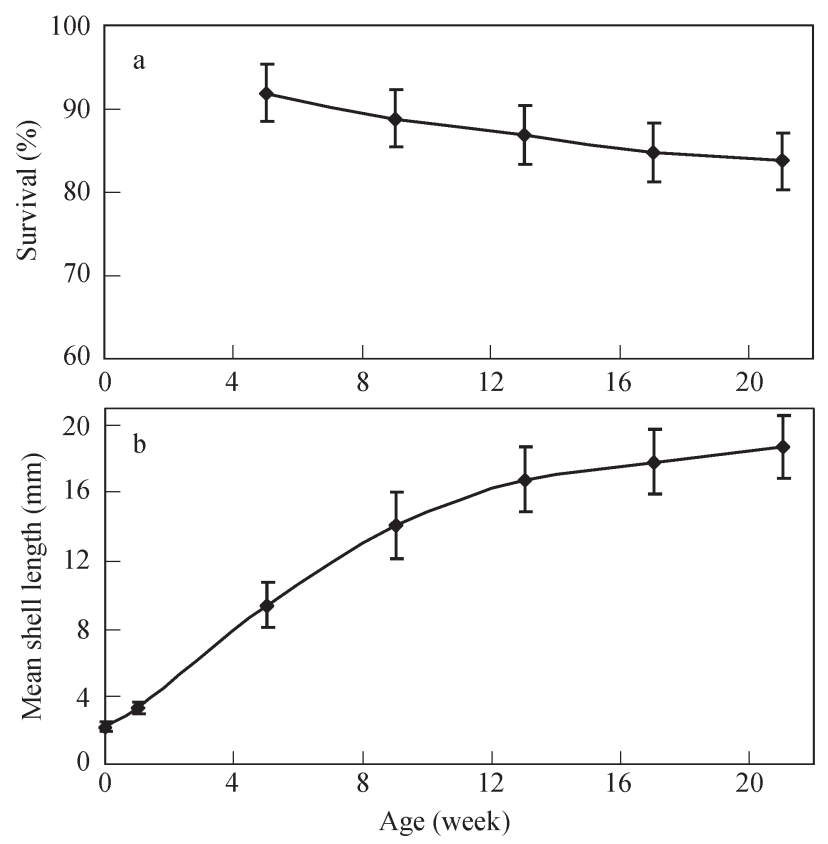

Fig. 3 Survival (a) and growth (b) of Bellamya aeruginosa during a culture period of 20 weeks. Error bars represent standard errors of means.

the shell lengths of 21-week-old females and males were $(17.76 \pm 1.46) \mathrm{mm}$ and $(17.59 \pm 1.68) \mathrm{mm}$, respectively. The snails could be sexed at 9 weeks of age (shell length $(14.12 \pm 1.97) \mathrm{mm}$. Female snails released their first newborn at approximately 18 weeks of age; thus they were estimated to reach maturity at around 16-17 weeks of age (i.e., 112-119 days old). The fecundity of freshly matured adult females was $(0.55 \pm 0.13)$ newborn/(female-day), and the average number of embryos carried by a gravid female was $19.33 \pm 2.54$.

\subsection{Assessment of sediment toxicity for 10 days with larvae}

The acute toxicity of $\mathrm{Cu}$-spiked sediments to the larvae of B. aeruginosa is shown in Table 4. No mortalities occurred in the control over the 10-day test, indicating that the test conditions were appropriate for sediment toxicity testing. $\mathrm{Cu}$ concentrations below $195 \mu \mathrm{g} / \mathrm{g}$ dw had no effect on survival. $\mathrm{Cu}$ concentrations of 570 and $872 \mu \mathrm{g} / \mathrm{g} \mathrm{dw}$ led to sharply decreased survival rates; only few snails survived at $872 \mu \mathrm{g} / \mathrm{g} \mathrm{dw}$. The calculated 10-day $\mathrm{LC}_{50}$ of $\mathrm{Cu}$ for larvae was $480 \mu \mathrm{g} / \mathrm{g}\left(\mathrm{CI}_{95 \%}\right.$ : $\left.[416 ; 536]\right)$. Because of the high mortality, data of growth and whole-body $\mathrm{Cu}$ burden are not presented for the $872 \mu \mathrm{g} / \mathrm{g} \mathrm{dw}$ treatment. The lowest observed effect concentration (LOEC) of $\mathrm{Cu}$ for both survival and growth of larvae was $195 \mu \mathrm{g} / \mathrm{g} \mathrm{dw}$ since significant decrease of survival and growth occurred at this level and higher. The average whole-body $\mathrm{Cu}$ burden of the snails subjected to each $\mathrm{Cu}$-spiked treatment was significantly higher than that of the control, and increased in a concentration-dependent manner; a sharp increase occurred at $570 \mu \mathrm{g} / \mathrm{g} \mathrm{dw}$.

\subsection{Assessment of sediment toxicity for 28 days with adults}

The data of survival, growth, tissue $\mathrm{Cu}$ burden, and biochemical endpoints are presented as combined values from both sexes due to the relatively small number of male samples in each replicate (Table 5 and Fig. 4). Compared to the controls, only $\mathrm{Cu}$ concentration of 570 $\mu \mathrm{g} / \mathrm{g}$ significantly decreased the survival rate and growth rate; otherwise the $\mathrm{Cu}$ concentrations had no effect on the
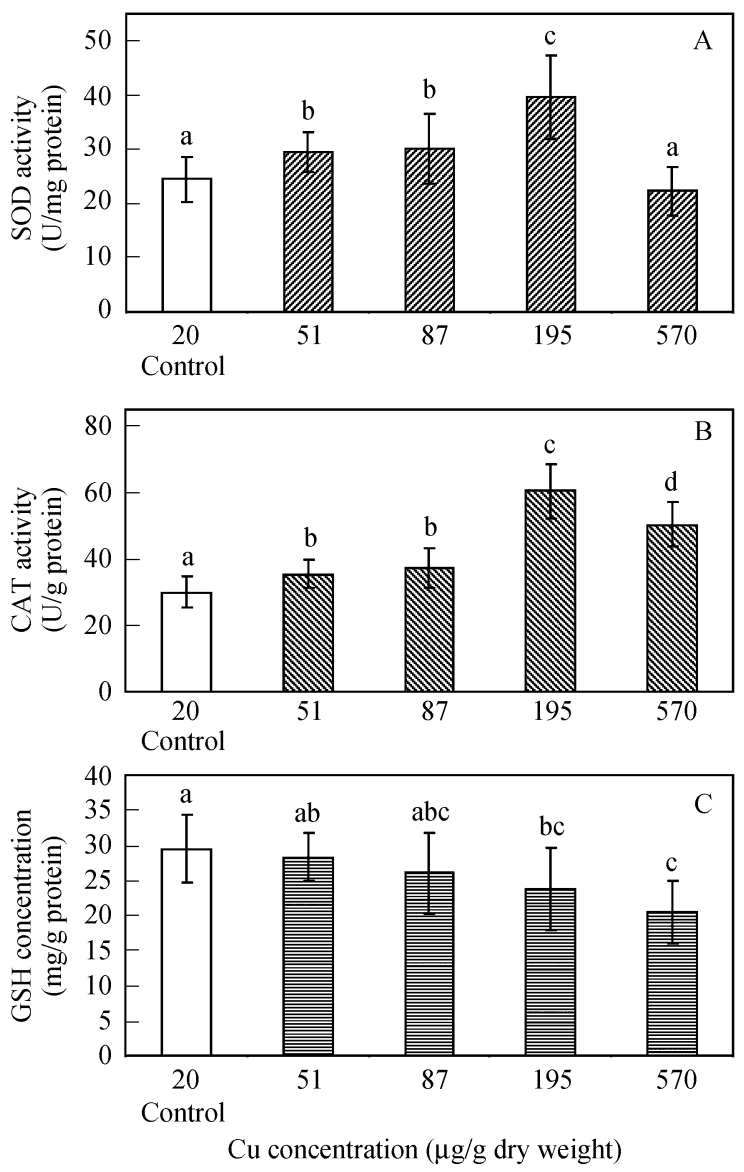

Fig. 4 SOD (A) and CAT activity (B), and the GSH concentration (C) in the hepatopancreas of adult Bellamya aeruginosa following 28-day chronic exposure to $\mathrm{Cu}$-spiked sediment. Error bars represent standard errors of means. Treatments with different letters differed significantly $(P$ $<0.05$, ANOVA post-hoc Tukey's honest significance difference multiple comparison test). 
Table 4 Mean survival rate, growth rate of shell length, and whole-body Cu burden of the larvae of Bellamya aeruginosa following 10-day exposure to $\mathrm{Cu}$-spiked sediment

\begin{tabular}{|c|c|c|c|c|c|c|}
\hline Endpoint & $20 \mu \mathrm{g} \mathrm{Cu} / \mathrm{g} \mathrm{dw}$ (control) & $51 \mu \mathrm{g} \mathrm{Cu} / \mathrm{g} \mathrm{dw}$ & $87 \mu \mathrm{g} \mathrm{Cu} / \mathrm{g} \mathrm{dw}$ & $195 \mu \mathrm{g} \mathrm{Cu} / \mathrm{g} \mathrm{dw}$ & $570 \mu \mathrm{g} \mathrm{Cu} / \mathrm{g} \mathrm{dw}$ & $872 \mu \mathrm{g} \mathrm{Cu} / \mathrm{g} \mathrm{dw}$ \\
\hline Mean survival rate $(\%)$ & 100 & 100 & 100 & $88.33^{*}(2.89)$ & $46.67 *(7.64)$ & $5.00 *(8.66)$ \\
\hline $\begin{array}{l}\text { Growth rate of shell } \\
\text { length }(\mu \mathrm{m} / \text { day })\end{array}$ & $220.71(14.75)$ & $217.48(19.70)$ & $234.97(17.32)$ & $127.63 *(19.25)$ & $123.83 *(19.86)$ & - \\
\hline $\begin{array}{l}\text { Whole-body Cu burden } \\
(\mu \mathrm{g} / \mathrm{g} \mathrm{dw})\end{array}$ & $26.92(0.52)$ & $38.89 *(1.19)$ & $60.52 *(1.48)$ & $88.48 *(2.36)$ & $185.09 *(6.51)$ & - \\
\hline
\end{tabular}

* Values significantly different from the corresponding control $(P<0.05$, Chi-square test for survival; ANOVA post-hoc Dunnett's test for growth and whole-body $\mathrm{Cu}$ burden). The value in parenthesis means SD.

Table 5 Mean survival rate, growth rate of shell length, gravidity, fecundity (average number of offspring per surviving adult), and tissue Cu burden of adult Bellamya aeruginosa following 28-day chronic exposure to $\mathrm{Cu}$-spiked sediment

\begin{tabular}{|c|c|c|c|c|c|}
\hline Endpoint & $20 \mu \mathrm{g} \mathrm{Cu} / \mathrm{g} \mathrm{dw}$ (control) & $51 \mu \mathrm{g} \mathrm{Cu} / \mathrm{g} \mathrm{dw}$ & $87 \mu \mathrm{g} \mathrm{Cu} / \mathrm{g} \mathrm{dw}$ & $195 \mu \mathrm{g} \mathrm{Cu} / \mathrm{g} \mathrm{dw}$ & $570 \mu \mathrm{g} \mathrm{Cu} / \mathrm{g} \mathrm{dw}$ \\
\hline Mean survival rate $(\%)$ & $97.72(3.61)$ & $95.83(3.69)$ & $97.82(3.17)$ & $96.89(4.67)$ & $83.33(7.22)^{*}$ \\
\hline Growth rate of shell length ( $\mu \mathrm{m} /$ day $)$ & $70.58(4.83)$ & $71.21(3.24)$ & $66.65(6.89)$ & $65.67(8.13)$ & $54.15(5.83)^{*}$ \\
\hline $\begin{array}{l}\text { Gravidity (\% gravid females per total } \\
\text { number of surviving females) }\end{array}$ & $69.47(4.79)$ & $68.07(8.83)$ & $65.07(7.29)$ & $63.43(3.98)$ & $41.67(7.22)^{*}$ \\
\hline Fecundity (newborn/(female·day)) & $2.53(0.39)$ & $2.63(0.45)$ & $2.28(0.26)$ & $1.76(0.23)^{*}$ & $1.37(0.30)^{*}$ \\
\hline \multicolumn{6}{|l|}{ Tissue $\mathrm{Cu}$ burden $(\mu \mathrm{g} \mathrm{Cu} / \mathrm{g} \mathrm{dw})$} \\
\hline Hepatopancreas & $30.01(4.98)$ & $33.88(8.14)$ & $49.94(15.04)$ & $115.97(23.45)^{*}$ & $244.95(52.58) *$ \\
\hline Gonad & $26.14(5.85)$ & $30.21(8.14)$ & $46.04(15.00)$ & $95.68(25.67)^{*}$ & $172.73(32.63) *$ \\
\hline Muscular foot & $7.75(2.00)$ & $16.01(3.45)$ & $20.07(5.01)$ & $29.68(5.80)^{*}$ & $43.05(9.72)^{*}$ \\
\hline
\end{tabular}

Values significantly different from the corresponding controls $(P<0.05$, Chi-square test for survival; ANOVA post-hoc Dunnett's test for other endpoints) The value in the parenthesis means SD.

survival and growth of adults. The gravidity of females was significantly lowered at $570 \mu \mathrm{g} / \mathrm{g} \mathrm{dw}$, whereas the fecundity was significantly decreased by $\mathrm{Cu}$ at $195 \mu \mathrm{g} / \mathrm{g}$ $\mathrm{dw}$ or higher. The tissue $\mathrm{Cu}$ burden was significantly elevated at $195 \mu \mathrm{g} / \mathrm{g} \mathrm{dw}$ or higher and ranked in the order of hepatopancreas $>$ gonad $>$ muscular foot. The hepatopancreatic SOD and CAT activity increased initially and then decreased with increasing sediment $\mathrm{Cu}$ concentrations (Fig. 4A, B). Both SOD and CAT activity significantly increased as $\mathrm{Cu}$ concentrations increased from 51 to 195 $\mu \mathrm{g} / \mathrm{g} \mathrm{dw}$, indicating that $\mathrm{Cu}$ significantly stimulated SOD and CAT activity. However, the SOD and CAT activities in response to $570 \mu \mathrm{g} / \mathrm{g} \mathrm{dw}$ were significantly lower than those at $195 \mu \mathrm{g} / \mathrm{g} \mathrm{dw}$, indicating the presence of inhibition. Compared with the control, GSH concentrations tended to decrease with increasing $\mathrm{Cu}$ concentrations, and significant decreases occurred at $195 \mu \mathrm{g} / \mathrm{g} \mathrm{dw}$ and beyond (Fig. 4C).

\section{Discussion}

\subsection{Laboratory culture of $\boldsymbol{B}$. aeruginosa}

Generally, organisms obtained by either direct fieldsampling or purchasing from local suppliers are not recommended as test organisms for sediment toxicity testing because some uncertain characteristics (such as unknown source, unidentified age, health, potential pollution stress) of these organisms may potentially confound the interpretation of bioassay results (USEPA, 2000). Therefore, successful laboratory culture of selected species is prerequisite for developing protocols of sediment toxicity. In the present study, due to its moderate size, relatively long life cycle and low fecundity, a sufficient batch of homogenous individuals of $B$. aeruginosa can rarely be harvested from a population maintained within a confined space. An appropriate culture device is therefore indispensable. The current culture experiment with $B$. aeruginosa showed that the established culture system was a relatively efficient and trouble-free device, in which the optimal conditions of dissolved oxygen and temperature for snails could be stably maintained through the filtration, reaeration, and thermoregulation of the overlying water. Indeed, except for daily cleaning of the filter cotton, timely replenishment of water loss, and routine feeding, no other efforts were demanded, thus minimizing perturbations to sediments and stress on the snails, and enhancing culture performance. In addition, unlike the oviparous gastropods (Ducrot et al., 2006), the reproductive feature of ovoviviparity also facilitated culture since no special care was needed at their early life stage. Therefore, rearing $B$. aeruginosa with this system was neither time nor labor consuming.

Culture experiments also indicated that the quality of the sediments used declined gradually over the culture period due to the decomposition of food residue and dead snails. Quality control of the sediments is necessary to perform long-term culture. A good solution for this issue is to renew sediments periodically (Ducrot et al., 2006), which requires a large amount of sediments. However, the reliable natural sediment sources with consistently acceptable clean sediments are not always available in the presence of extensive aquatic pollution. Artificial sediment based on unpolluted soil may be a practicable alternative because the use of artificial sediments can allow standardization of test organism cultures and eliminate interferences caused by the presence of endogenous organisms in natural sediments (USEPA, 2000; Pasteris et al., 2003). In our laboratory culture, the survival rates as high as $80 \%$ and early maturation (4 months), compared with more than 6 months in natural habitats (Chen and Song, 1975), demonstrated clearly that the artificial sediments used were favorable 
to the growth and development of B. aeruginosa. Under laboratory culture conditions (Table 1), the snails can breed three generations in one year.

The fecundity of the laboratory population was approximately twice that in the field population $(0.24$ newborn/(female·day)) (Chen and Song, 1975), indicating that the commercial fish food satisfied the nutritional requirements of $B$. aeruginosa for reproduction. The use of eight culture chambers with 90 adults at a female to male ratio of 2:1 could maintain a continuous supply of newborn throughout the year. It should be noted that, in order to realize planned culture, juvenile snails should be sexed in a timely manner and reared in separate culture chambers to avoid unexpected mating. Nevertheless, due to the use of artificial sediments, the obtained values for lifehistory traits might be different from the values in natural sediments.

\subsection{Assessment of sediment toxicity}

The survival rates of the controls in both sediment toxicity tests were $100 \%$ and $97.92 \%$, respectively, which are higher than the minimum allowable value required for standardized tests (USEPA, 2000) and indicate that the test conditions were suitable for sediment toxicity tests. The LOEC of the $\mathrm{Cu}$-spiked sediment for survival and growth of the larvae was lower than that in the adults (195 vs. $570 \mu \mathrm{g} / \mathrm{g} \mathrm{dw}$ ), indicating that the larvae were more sensitive to the $\mathrm{Cu}$-spiked sediment than the adults. This difference in sensitivity to $\mathrm{Cu}$ between the larvae and the adults seemed to be associated with their capabilities to metabolize $\mathrm{Cu}$, since the $\mathrm{Cu}$ burdens were obviously higher in larvae than that in adults. In any case, tissue $\mathrm{Cu}$ burden in adults might not be a useful indicator for chronic exposure to low concentrations. The distribution of $\mathrm{Cu}$ in tissues agreed with published observations showing that major microcystins were present in the hepatopancreas of B. aeruginosa (Zhang et al., 2007). As far as the 10day LOEC was concerned, B. aeruginosa seemed to be more sensitive to sediment $\mathrm{Cu}$ exposure than the two standard test species $H$. azteca and C. tentans, with 10-day LOECs for growth and survival of $>2010 \mu \mathrm{g} / \mathrm{g}$ (Huggett et al., 1999). The LOEC of toxicity endpoints proved that both survival and growth of $B$. aeruginosa responded sensitively to the adverse effects of $\mathrm{Cu}$ in the 10-day assessment of acute toxicity with larvae. In the 28-day assessment of chronic toxicity with adults, fecundity was a reliable endpoint indicating $\mathrm{Cu}$ toxicity to reproduction, whereas survival, growth, and gravidity did not appear to be sensitive endpoints.

Antioxidant defense systems have been widely studied in various aquatic organisms (such as mollusks and oligochaetes) exposed experimentally to chemicals or collected from polluted areas, and oxidative stress components such as SOD, CAT, GSH, and MT (metallothionein) have been frequently used as exposure or effect biomarkers of contaminants (Bergayou et al., 2009; Mosleh et al., 2007). It is well known that SOD and CAT are enzymes that detoxify reactive oxygen species in the cells. In the present study, hepatopancreatic SOD and CAT exhibited high sensitivity to $\mathrm{Cu}$ stress because $\mathrm{Cu}$ exposure at low concentration $(51 \mu \mathrm{g} / \mathrm{g})$ could cause significant increase of their activities. Similar results reported by Xiong and You (2002) showed that SOD and CAT in the whole visceral hump of $B$. aeruginosa were relatively sensitive to in situ exposure to polluted river sediments. Therefore, in $B$. aeruginosa, hepatopancreatic SOD and CAT can be used as effective biomarkers for contaminant-induced oxidative damage. Moreover, the distinct hormesis (stimulation at low doses but inhibition at high doses) (Calabrese and Lu, 2006) of SOD activity (Fig. 4A) suggested that SOD can be used as a more suitable biomarker for exposure to low concentrations of $\mathrm{Cu}$ than CAT and GSH. In general, GSH reacts readily with heavy metal ions and thus participates in detoxification (Kuroshima, 1995). In our study, the hepatopancreatic GSH content in snails exposed to high concentrations of $\mathrm{Cu}(570 \mu \mathrm{g} / \mathrm{g} \mathrm{dw}) \mathrm{sig}$ nificantly decreased, indicating that high concentration of accumulated $\mathrm{Cu}$ markedly depleted GSH and thus induced $\mathrm{Cu}$ toxicity as evidenced by significantly decreased SOD activity.

Compared to reported small freshwater gastropods, such as V. piscinalis (Ducrot et al., 2006) and P. antipodarum (Duft et al., 2007), our bioassay with B. aeruginosa showed some distinct advantages. Its relatively large size (adults with shell length of more than $17 \mathrm{~mm}$ ) facilitates experimental handling and provides sufficient tissue biomass for bioassays, and thus enables identification of potential endpoints for sublethal or chronic toxicity. For example, multi-endpoints can be measured simultaneously with the relatively large 50-mg hepatopancreas.

Although our sediment toxicity test used artificial sediments instead of natural sediments, this practice simply provided a general method for evaluating toxicity of sediments spiked with specific chemicals. Actually, the use of artificial sediment may eliminate or control the variation in sediment physico-chemical characteristics (USEPA, 2000). In a similar study about toxicity of $\mathrm{Cu}$-spiked sediments to Tubifex tubifex, Pasteris et al. (2003) suggested that when artificial sediment was $\mathrm{Cu}$-spiked and used in bioassays, an adequate and consistent matching between target and measured concentrations and a definite dose-response curve were obtained, which was also confirmed by our bioassay. Nevertheless, the sensitivity of $B$. aeruginosa to $\mathrm{Cu}$ in the current study may only be representative of the experimental conditions instead of natural sediments.

The life history traits and the results from the assessment of toxicity of the $\mathrm{Cu}$-spiked sediment proved that $B$. aeruginosa appears to have a great potential as a test species for sediment toxicity tests in China. Based on the life history of B. aeruginosa, the assessment of sediment toxicity can be carried out through the developmental stages of larvae (0-28 days old), juveniles (28-112 days old) and adults (over 112 days old). Due to the thin and fragile shell of newborns and their behaviors of inhabiting non-sediment substrates, 7-day-old larvae instead of newly born individuals are recommended for use. However, due to the relatively long life cycle of $B$. aeruginosa, the 
assessment of sediment toxicity over a single life cycle or even generations requires an extended experimental period.

Further investigations are warranted to ascertain acute and chronic sensitivity of $B$. aeruginosa to a wide range of contaminants of concern in freshwater ecosystems, and to develop some sensitive bioassay endpoints or biomarkers.

\section{Conclusions}

Under the designed conditions, B. aeruginosa was successfully cultured with ideal culture performances and reached sexual maturity earlier than field populations. The test conditions of our study proved to be suitable for $B$. aeruginosa. Its moderate size facilitated assays with individuals of different life stages. Compared to the routine test species, $B$. aeruginosa seems to be a sensitive species. Our findings suggest $B$. aeruginosa as a suitable species for the assessment of sediment toxicity. Further investigations are still required to understand its acute and chronic sensitivity to a wide range of contaminants, and to identify other effective bioassay endpoints or biomarkers for the assessment of sediment toxicity.

\section{Acknowledgments}

This work was supported by the National Natural Science Foundation of China (No. 20677021) and the Science Foundation of Jishou University (No. jsdxkyzz200101).

\section{References}

Adams W J, Kimerle R A, Barnett Jr J W, 1992. Sediment quality and aquatic life assessment. Environmental Science $\mathcal{E}$ Technology, 26(10): 1864-1875.

Anderson B, Nicely P, Gilbert K, Kosaka R, Hunt J, Phillips B, 2004. Overview of Freshwater and Marine Toxicity Tests: A Technical Tool for Ecological Risk Assessment. California Environmental Protection Agency Office of Environmental Health Hazard Assessment Reproductive and Cancer Hazard Assessment Section Ecotoxicology Unit. www.oehha.ca.gov/ecotox/documents.

ASTM (American Society for Testing and Materials), 2002. Standard guide for designing biological tests with sediments (ASTM designation: E 1525-02). In: Annual Book of ASTM Standards. Vol 11.05. Philadelphia, PA. 844-868.

ASTM (American Society for Testing and Materials), 2003. Test method for measuring the toxicity of sediment-associated contaminants with freshwater invertebrates. E1706-2002.

Bergayou H, Mouneyrac C, Pellerin J, Moukrim A, 2009. Oxidative stress responses in bivalves (Scrobicularia plana, Cerastoderma edule) from the Oued Souss estuary (Morocco). Ecotoxicology and Environmental Safety, 72(3): 765-769.

Calabrese E J, Lu R, 2006. Hormesis has emerged as a more common and fundamental dose-response model than the threshold or linear-no-threshold (LNT) models. Journal of Toxicology, 20(2): 117-118.

Chen Q Y, 1987. A preliminary study on the population dynamics and annual production of Bellamya aeruginosa (Reeve) in Lake Donghu, Wuhan. Acta Hydrobiologica Sinica, 11(2): 117-130.
Chen Q Y, Liang Y L, Song G B, Wang S D, 1975. Ecological distributions and population densities of mollusca in Lake Donghu, Wuchang. Acta Hydrobiologica Sinica, 5(3): 371379.

Chen Q Y, Song G B, 1975. A preliminary study on reproduction and growth of the snail, Bellamya aeruginosa (Reeve). Acta Hydrobiologica Sinica, 5(4): 519-534.

Courdassier M, de Vaufleury A, Crini N, Scheifler R, Badot $\mathrm{P}, 2005$. Assessment of whole effluent toxicity on aquatic snails: bioaccumulation of $\mathrm{Cr}, \mathrm{Zn}$, and $\mathrm{Fe}$, and individual effects in bioassays. Environmental Toxicology and Chemistry, 24(1): 198-204.

Ducrot V, Cognat C, Mons R, Mouthon J, Garric J, 2006. Development of rearing and testing protocols for a new freshwater sediment test species: The gastropod Valvata piscinalis. Chemosphere, 62(8): 1272-1281.

Duft M, Schmitt C, Bachmann J, Brandelik C, Schulte-Oehlmann U, Oehlmann J, 2007. Prosobranch snails as test organisms for the assessment of endocrine active chemicals - an overview and a guideline proposal for a reproduction test with the freshwater mudsnail Potamopyrgus antipodarum. Ecotoxicology, 16(1): 169-182.

Gomot A, 1998. Toxic effects of cadmium on reproduction, development, and hatching in the freshwater snail Lymnaea stagnalis for water quality monitoring. Ecotoxicology and Environmental Safety, 41(3): 288-297.

Greenstein D, Bay S, Anderson B, Chandler G T, Farrar J D, Keppler $\mathrm{C}$ et al., 2008. Comparison of methods for evaluating acute and chronic toxicity in marine sediments. Environmental Toxicology and Chemistry, 27(4): 933-944.

Hamilton M A, Russo R C, Thurston R V, 1977. Trimmed Spearman-Karber method for estimating median lethal concentrations in toxicity bioassays. Environmental Science $\mathcal{E}$ Technology, 11(7): 714-719.

Huggett D B, Gillespie Jr W B, Rodgers Jr J H, 1999. Copper bioavailability in Steilacoom Lake sediments. Archives of Environmental Contamination and Toxicology, 36(2): 120123.

Kuroshima R, 1995. Hepatic metallothionein and glutathione levels in Red Sea bream. Comparative Biochemistry and Physiology Part C: Pharmacology, Toxicology and Endocrinology, 110(1): 95-100.

Leung K M Y, Grist E P M, Morley N J, Morritt D, Crane M, 2007. Chronic toxicity of tributyltin to development and reproduction of the European freshwater snail Lymnaea stagnalis (L.). Chemosphere, 66(7): 1358-1366.

Liu Y Y, Zhang W Z, Wang Y X, 1993. Medical Malacology. China Ocean Press, Beijing.

Livingstone D R, 2001. Contaminant-stimulated reactive oxygen species production and oxidative damage in aquatic organisms. Marine Pollution Bulletin, 42(8): 656-666.

Ma T W, Wang Z J, Gong S J, 2007. Comparative Sensitivity in Chinese Rare Minnow (Gobiocypris rarus) and Japanese Medaka (Oryzias latipes) Exposed to Ethinylestradiol. Journal of Environmental Science and Health, Part A, 42(7): 889-894.

Martinez E A, Moore B C, Schaumloffel J, Dasgupta N, 2004. Effects of exposure to a combination of zinc- and leadspiked sediments on mouthpart development and growth in Chironomus tentans. Environmental Toxicology and Chemistry, 23(3): 662-667.

Mcgee B L, Fisher D J, Wright D A, Yonkos L T, Ziegler G P, Turley S D et al., 2004. A field test and comparison of acute and chronic sediment toxicity tests with the estuarine 
amphipod Leptocheirus plumulosus in Chesapeake Bay, USA. Environmental Toxicology and Chemistry, 23(7): 1751-1761.

Mosleh Y Y, Paris-Palacios S, Ahmed M T, Mahmoud F M, Osman M A, Biagianti-Risbourg S, 2007. Effects of chitosan on oxidative stress and metallothioneins in aquatic worm Tubifex tubifex (Oligochaeta, Tubificidae). Chemosphere, 67(1): 167-175.

O'Connor T P, Paul J F, 2000. Misfit between sediment toxicity and chemistry. Marine Pollution Bulletin, 40(1): 59-64.

Oehlmann J, Schulte-Oehlmann U, Tillmann M, Markert B, 2000. Effects of endocrine disruptors on prosobranch snails (Mollusca: Gastropoda) in the laboratory. Part I: Bisphenol A and octylphenol as xeno-estrogens. Ecotoxicology, 9(6): 383-397.

Oetken M, Nentwig G, Loffler D, Ternes T, Oehlmann J, 2005. Effects of pharmaceuticals on aquatic invertebrates. Part I. The antiepileptic drug carbamazepine. Archives of Environmental Contamination and Toxicology, 49(3): 353-361.

Pasteris A, Vecchi M, Reynoldson T B, Bonomi G, 2003. Toxicity of copper-spiked sediments to Tubifex tubifex (Oligochaeta, Tubificidae): a comparison of the 28-day reproductive bioassay with a 6-month cohort experiment. Aquatic toxicology, 65(3): 253-265.

Ren N, Ji S, Zheng Y, 2007. Pollution characteristics of heavy metals in bottom sediments of the west lake of Chaozhou. Guangdong Trace Elements Science, 14(2): 47-50.

Ringenary M J, Molof A H, Tanacredi J T, Schreibman M P, Kostarelos K, 2007. Long-term sediment bioassay of lead toxicity in two generations of the marine amphipod Elasmopus laevis, S.I. Smith (1873). Environmental Toxicology and Chemistry, 26(8): 1700-1710.

Simpson S L, Angel B M, Jolley D F, 2004. Metal equilibration in laboratory-contaminated (spiked) sediments used for the development of whole-sediment toxicity tests. Chemosphere, 54(5): 597-609.

USEPA (US Environmental Protection Agency), 2000. Methods for measuring the toxicity and bioaccumulation of sediment-associated contaminants with freshwater invertebrates (2nd ed.). EPA-600-R-99-064. Technical Report. Washington DC.

Xiong Y Q, You W H, 2002. Preliminary study on effects of SOD and catalase of Bellamya aeruginosa raised in Suzhou Creek. Journal of East China Normal University, 4: 96101.

Zhang D W, Xie P, Liu Y Q, Chen J, Liang G D, 2007. Bioaccumulation of the hepatotoxic microcystins in various organs of a freshwater snail from a subtropical Chinese lake, Taihu Lake, with dense toxic microcystis blooms. Environmental Toxicology and Chemistry, 26(1): 171-176. 